\title{
Altered Serotonergic Neurotransmission but Normal Hypothalamic-Pituitary-Adrenocortical Axis Activity in Mice Chronically Treated with the Corticotropin-Releasing Hormone Receptor Type I Antagonist NBI 30775
}

\author{
Akihiko Oshima ${ }^{1,2}$, Cornelia Flachskamm', Johannes MHM Reul ${ }^{1,3}$, Florian Holsboer' and Astrid CE \\ Linthorst ${ }^{*, 1,3}$ \\ 'Max Planck Institute of Psychiatry, Sections of Neurochemistry and Neuropsychopharmacology, Munich, Germany
}

\begin{abstract}
Antagonists of the corticotropin-releasing hormone receptor type I ( $\mathrm{CRH}-\mathrm{RI})$ are regarded as promising tools for the treatment of stress-related psychiatric disorders. Owing to the intricate relationship between $\mathrm{CRH}$ and serotonin (5-HT), we studied the effects of chronic oral treatment of C57BI6/N mice with the CRH-RI antagonist NBI 30775 (formerly known as RI21919) on hippocampal serotonergic neurotransmission during basal (on 15th day of treatment) and stress (forced swimming; on 16th day of treatment) conditions by in vivo microdialysis. Given the important role of $\mathrm{CRH}$ in the regulation of hypothalamic-pituitary-adrenocortical (HPA) axis activity and behavior, the effects of NBI 30775 on dialysate-free corticosterone levels, and on home cage and forced swimmingrelated behavior were also assessed. Chronic administration of NBI 30775 (I8.4 $\pm 0.9 \mathrm{mg} / \mathrm{kg} / \mathrm{day})$ did not result in alterations in food consumption and body weight. NBI 30775 caused complex changes in hippocampal serotonergic neurotransmission. Whereas no effects on the diurnal rhythms of 5-HT and its metabolite 5-hydroxyindoleacetic acid were found, the responses of the neurotransmitter and its metabolite to 10 min of forced swim stress were reduced and prolonged, respectively. NBI 30775 did not change free corticosterone levels over the diurnal rhythm. Moreover, NBI 30775-treated mice showed a similar forced swim stress-induced increase in corticosterone as observed in the control group. No effects of NBI 30775 on home cage, and swim stress-related active behaviors (climbing, swimming) and immobility were found. Thus, whereas chronic antagonism of $\mathrm{CRH}-\mathrm{RI}$ did not compromise HPA axis performance and behavior, distinct changes in serotonergic neurotransmission developed. Owing to the important role of 5-HT in the pathophysiology of mood and anxiety disorders, the latter observation may contribute to the therapeutical efficacy of $\mathrm{CRH}-\mathrm{RI}$ antagonists in these illnesses.

Neuropsychopharmacology (2003) 28, 2 I48-2159, advance online publication, 13 August 2003; doi: I0.1038/sj.npp. 1300267
\end{abstract}

Keywords: corticotropin-releasing hormone; serotonin; corticosterone; stress; antagonist; mice

\section{INTRODUCTION}

In the majority of severely depressed patients, hyperactivity or dysregulation of the hypothalamic-pituitary-adrenocor-

*Correspondence: Dr ACE Linthorst, Max Planck Institute of Psychiatry, Section of Neurochemistry, Kraepelinstrasse 2, D-80804 Munich, Germany, Tel: + 498930622 589, Fax: + 498930622 610, E-mail: linthors@mpipsykl.mpg.de

Present address: Department of Psychiatry, Tatebayashi Kosei Hospital, 262-I Narushima-cho, Tatebayashi, Gunma 374-8533, Japan ${ }^{3}$ Future address (from August I, 2003): University Research Centre for Neuroendocrinology, The Dorothy Hodgkin Building, University of Bristol, Whitson Street, Bristol, BSI 3NY, UK.

Received I 8 February 2003; revised 03 June 2003; accepted 05 June 2003

Online publication: 13 June 2003 at http://www.acnp.org/citations/ Npp06 | 30303007 I/default.pdf tical (HPA) axis can be assessed by baseline measurements and neuroendocrine function tests. Characteristic features not only include hypercortisolemia (Linkowski et al, 1985; Deuschle et al, 1997) and abnormal outcome of several neuroendocrine challenge tests (eg Carroll et al, 1981; Von Bardeleben and Holsboer, 1989), but also hyperactivity of corticotropin-releasing hormone $(\mathrm{CRH})$ neurons (reviewed in Nemeroff, 1996; Holsboer, 1999; Reul and Holsboer, 2002). Enhanced levels of $\mathrm{CRH}$ in the cerebrospinal fluid (Nemeroff et al, 1984), decreased numbers of CRH-binding sites in the frontal cortex (Nemeroff et al, 1988), an increased number of $\mathrm{CRH}$-expressing neurons in the hypothalamic paraventricular nucleus (Raadsheer et al, 1994), and an elevated level of CRH mRNA expression in this nucleus (Raadsheer et al, 1995) have been reported in depressed patients. Based on the key role of CRH in fear and anxiety and in the regulation of sympathetic drive (for 
references see Owens and Nemeroff, 1991), it is thought that hyperactivity of this neuropeptide system is also involved in the behavioral and autonomic changes observed in depression and anxiety.

Historically and psychopharmacologically, the monoamine hypothesis of depression has drawn the most attention during the past decades. Generally, it is now thought that in depression both serotonergic and norepinephrine neurotransmission are disturbed (for references see Maes and Meltzer, 1995; Ressler and Nemeroff, 2000). As serotonin (5-HT) as well as norepinephrine modulate responses to stress, the imbalance between these two neurotransmitters may have pronounced consequences for the performance of neural circuits engaged in behavioral, neuroendocrine, and autonomic aspects of the stress response. Some years ago, we have shown that chronic elevation of brain $\mathrm{CRH}$ causes a decreased responsiveness of hippocampal 5-HT to stress in rats (Linthorst et al, 1997). Moreover, life-long deficiency of CRH receptor type 1 (CRH-R1) in mutant mice results in an altered adjustment of the 5-HT system under basal and stress conditions (Peñalva et al, 2002). These observations suggest that long-term alterations at the level of the $\mathrm{CRH}$ system have marked consequences for serotonergic neurotransmission. Interactions between $\mathrm{CRH}$ and 5-HT are also underscored by the observation that acute intracerebroventricular (i.c.v.) administration of CRH (and its congener urocortin (Ucn)) increases rat hippocampal levels of 5-HT and its metabolite 5-hydroxyindoleacetic acid (5-HIAA) (Linthorst et al, 2002), whereas bimodal, dose-dependent effects were observed in the striatum and lateral septum (Price et al, 1998; Price and Lucki, 2001). Electrophysiological studies have shown that $\mathrm{CRH}$ regulates the firing rate of 5-HT neurons in the dorsal raphe nucleus (Kirby et al, 2000; Lowry et al, 2000). Interactions between CRH (and CRH-R) and 5-HT are also confirmed at the neuroanatomical level (Sakanaka et al, 1987; Swanson et al, 1983; Chalmers et al, 1995; Kirby et al, 2000; Bittencourt and Sawchenko, 2000; Lowry et al, 2000; Van Pett et al, 2000; Valentino et al, 2001).

Given the bidirectional interactions between the $\mathrm{CRH}$ system and serotonin and their relevance for the etiology of affective disorders, we now aimed to demonstrate, using in vivo microdialysis in mice, the effects of chronic oral administration of the CRH-R1 antagonist NBI 30775 on serotonergic neurotransmission in the hippocampus; a limbic brain region intricately involved in behavioral and neuroendocrine responses to stress. Moreover, because of the role of CRH-R1 in the regulation of the HPA axis we also studied the effects of NBI 30775 on free corticosterone levels in dialysates under basal and forced swim stress conditions. This study focuses on the effects of chronic administration of NBI 30775 for two reasons. First, CRH-R1 antagonists are now extensively discussed as new therapeutical agents in the treatment of depression and anxiety. In various animal models, nonpeptidergic CRH-R1 antagonists, such as CP154,526, antalarmin, SSR125543A, and NBI 30775, indeed demonstrate antidepressant and anxiolytic properties after acute or chronic administration (Deak et al, 1999; Lundkvist et al, 1996; Schulz et al, 1996; Griebel et al, 1998, 2002; Arborelius et al, 2000; Millan et al, 2001; Heinrichs et al, 2002; Gutman et al, 2003). Importantly, a first study in 20 depressed patients showed the therapeutical potential of the
CRH-R1 antagonist NBI 30775 (Zobel et al, 2000; NBI 30775 is referred to as R121919 in this study). Second, based on our observations regarding hippocampal serotonergic neurotransmission and HPA axis regulation in life-long CRH-R1-deficient mice (Peñalva et al, 2002), we planned to compare the consequences of chronic pharmacological antagonism of CRH-R1 (this study) with those resulting from a genetical manipulation of the receptor.

\section{METHODS AND MATERIALS}

\section{Animals}

Male $\mathrm{C} 57 \mathrm{Bl} / 6 \mathrm{~N}$ mice aged 12-16 weeks were purchased from Charles River (Sulzfeld, Germany). Upon arrival, mice were housed individually in polycarbonate cages (Type 2) under standard housing conditions (lights on between 0600 and 1800 ; temperature $22-23^{\circ} \mathrm{C}$; relative humidity $40-60 \%$ ) and with food pellets and water available ad libitum. At 2 weeks after arrival, the mice were housed in special plexiglass cages $(l \times w \times h=25 \times 15 \times 35 \mathrm{~cm})$ in the experimental room and were adapted to a liquid diet (see below).

The experimental protocols were approved by the Ethical Committee on Animal Care and Use of the Government of Bavaria, Germany.

\section{Oral Treatment with NBI 30775}

To avoid confounding stress-related effects of repeated systemic injections, NBI 30775 was administered via the food. This strategy has recently successfully been used to demonstrate the effects of putative antidepressant glucocorticoid receptor antagonists on HPA axis activity (Bachmann et al, 2003). Mice were adapted to eat a liquid diet starting 5 days before surgery. Lieber DeCarli Regular Rodent Liquid Diet Control (\#710027; Dyets, Bethlehem, PA, USA) was used at a concentration of $222 \mathrm{mg} / \mathrm{ml}$ tap water. The liquid diet was filled into feeding tubes with a scale for the measurement of the consumed volume of food (Dyets, Bethlehem, PA, USA). The liquid diet was prepared fresh every day at around 1600. At this time point, the volume eaten during the previous $24 \mathrm{~h}$ was measured. Only on the first day mice were also given a few food pellets in the cage. During the entire experiment, mice had free access to a bottle with tap water. After surgery the feeding with liquid diet continued. Mice tolerated the liquid diet very well; no loss of body weight was observed and the feces had a normal consistency.

At 2 days after the surgery, one group of mice was further given liquid diet (control group), whereas in a second group of animals treatment with the CRH-R1 antagonist NBI 30775 began (NBI 30775 group). NBI 30775 was mixed through the liquid diet in a concentration of $33.3 \mu \mathrm{g} / \mathrm{ml}$ liquid food. This concentration was chosen based on the average volume of liquid diet eaten per day and the intended dose of $20 \mathrm{mg}$ NBI 30775 per kg body weight (see Results). The NBI 30775-containing diet was also prepared fresh every day (1600). Animals were treated with NBI 30775 until the end of the experiment. On the first (diurnal rhythm) and second (forced swim stress) experimental days, mice had received NBI 30775 for 15 and 16 days, 
respectively. The intended dose of $20 \mathrm{mg} / \mathrm{kg} /$ day was selected based on its anxiolytic effects in rats (Keck et al, 2001; Heinrichs et al, 2002), and its high displacement efficiency of ${ }^{125} \mathrm{I}$-oCRH and ${ }^{125} \mathrm{I}$-sauvagine binding to $\mathrm{CRH}$ $\mathrm{R} 1$ receptors in the rat brain and pituitary (Keck et al, 2001; Heinrichs et al, 2002).

\section{Surgery and Microdialysis Procedure}

Surgery and microdialysis were largely performed as described before (Linthorst et al, 2000; Peñalva et al, 2002). Briefly, 17 days before the first experimental day, mice were, under isoflurane anesthesia (Curamed, Karlsruhe, Germany), implanted with a sterile, stainless-steel guide cannula (made from a $22 \mathrm{G}$ injection needle) entering the dorsal site of the hippocampus (coordinates with bregma as reference: lateral $3.2 \mathrm{~mm}$, posterior $2.9 \mathrm{~mm}$, ventral $1.7 \mathrm{~mm}$ ). In addition, a small peg was adhered to the skull to connect to a dual channel liquid swivel and counterbalancing arm (Instech Laboratories, Plymouth Meeting, PA, USA) during the experiment.

At 15 days after the surgery, a microdialysis probe was implanted into the hippocampus under a light and shortlasting isoflurane anesthesia (CMA/11, CMA/Microdialysis $\mathrm{AB}$, Stockholm, Sweden; membrane: cuprophane, molecular cutoff $6000 \mathrm{Da}$; outer diameter $0.24 \mathrm{~mm}$, length $3 \mathrm{~mm}$ ). The microdialysis probe was perfused with physiological Ringer solution at a flow rate of $2 \mu \mathrm{l} / \mathrm{min}$. Microdialysis samples were collected in a refrigerated microsampler (Univentor, Malta) and were stabilized with ascorbic acid (end concentration in sample $0.10-0.125 \mathrm{mM}$ ). Samples were used to measure 5-HT, 5-HIAA, and free corticosterone (see below). For more details, see Linthorst et al (2000) and Peñalva et al (2002).

Experiments, on four mice simultaneously, were performed on day 2 (first experimental day; diurnal rhythm) and day 3 (second experimental day; forced swim stress) after the insertion of the microdialysis probe.

First experimental day: assessment of the diurnal rhythms of hippocampal serotonergic neurotransmission, free corticosterone, and behavioral activity. At 2 days after insertion of the microdialysis probe (mice were treated with NBI 30775 for 15 days), 30-min samples were collected between 0900 and 2000 followed by the collection of 60 -min samples between 2000 and 0900 to monitor the diurnal rhythms of 5-HT, 5-HIAA, and free corticosterone. Microdialysis samples were split for high-pressure liquid chromatography (HPLC) and radioimmunoassay measurements (see below). The behavior of the mice in their home cages was registered on video tape for later scoring (scoring in intervals of $1 \mathrm{~min}$ ). The video recording equipment in our laboratory did not allow to register behavior during the full $24 \mathrm{~h}$ of the light/dark cycle. Based on our earlier work (Linthorst et al, 1999), behavior was, therefore, monitored during three periods, that is, between 0900 and 1800 during the light phase, and between 1800 and 2300, and 0400 and 0600 during the dark phase. Mice show high levels of behavioral activity during the first half of the dark period, and also increased activity during the last $2 \mathrm{~h}$ of the dark phase (Linthorst et al, 1999).
Second experimental day: responsiveness of hippocampal serotonergic neurotransmission, free corticosterone, and behavior to forced swim stress. To study the effects of long-term treatment with the CRH-R1 antagonist NBI 30775 on the responsiveness of hippocampal serotonergic neurotransmission and the HPA axis, mice were submitted to a forced swim stress paradigm on the third day after the insertion of the microdialysis probe (mice were treated with NBI 30775 for 16 days). Microdialysis samples were either used for HPLC or radioimmunoassay analysis. To assess baseline levels, eight 15-min samples were collected between 0900 and 1100 . Then mice were forced to swim for $10 \mathrm{~min}$ as described below (1100-1110). Poststress levels were determined until 1510 (sixteen 15-min samples). Behavioral activity in the home cage was registered on video tape during the entire experiment for later scoring $(30 \mathrm{~s}$ intervals). Moreover, we scored the behavior during the swimming period in detail (see below).

\section{Forced Swim Stress}

Mice were forced to swim for $10 \mathrm{~min}$ in a glass beaker (diameter $12.5 \mathrm{~cm}$ ) containing water of $25^{\circ} \mathrm{C}$. The water depth was $11.5 \mathrm{~cm}$; the mice could not touch the bottom of the glass beaker with their paws or tail. After $10 \mathrm{~min}$, the mice were carefully dried and returned to their home cage. The behavior displayed by the animals during swimming was scored from video tape in intervals of $5 \mathrm{~s}$. Behavior was classified in the following three categories as also described in rats by Lucki and coworkers (Detke et al, 1995): (1) climbing and struggling: active movements of the forepaws in and out of the water and resulting in an upward movement of the body (mostly directed against the wall of the glass beaker); (2) swimming: active swimming motions more than necessary to keep the head above the water surface (characteristic feature is a fast paddling movement of the hindlimbs); (3) floating: immobile position during which only small movements to keep the head above the water surface were allowed. No diving was observed. The amount of these three behaviors was then expressed as the percentage of the total number of counts.

\section{Measurement of 5-HT, 5-HIAA, and Corticosterone}

Dialysates were analyzed for 5-HT and 5-HIAA without prior purification by HPLC combined with electrochemical detection. The chromatography system consisted of a Sunflow 100 isocratic pump (Sunchrom, Friedrichsdorf, Germany), a mobile phase degasser (Sunchrom, Friedrichsdorf, Germany), a Mistral column thermostat (Spark Holland Instruments, Emmen, The Netherlands), a cooled Triathlon autosampler (Spark Holland Instruments, Emmen, The Netherlands), an electrochemical detector (Antec Leyden, Zoeterwoude, The Netherlands), and a Gynkosoft chromatography data system (Dionex, Idstein, Germany). An aliquot of each dialysate was injected (injected volume depended on dialysate sample duration and aliquot used for radioimmunoassay measurements) using the $\mu$ l-pickupmethod of the autosampler. 5-HT and 5-HIAA were separated on a YMC Pro C18 column $(150 \times 3.0 \mathrm{~mm}$; particle size $3 \mu \mathrm{m}$; YMC Europe $\mathrm{GmbH}$, Schermbeck, Germany). The flow rate of the pump and the temperature 
of the column thermostat were set at $400 \mu \mathrm{l} / \mathrm{min}$ and $30^{\circ} \mathrm{C}$, respectively. The mobile phase consisted of $20 \%$ methanol, $75 \mathrm{mM}$ sodium phosphate $\left(\mathrm{NaH}_{2} \mathrm{PO}_{4}\right), 0.2 \mathrm{mM}$ sodium octyl sulfate and $0.1 \mathrm{mM}$ EDTA (pH 4.6). 5-HT and 5-HIAA were quantified by electrochemical detection, with the detector potential set at $550 \mathrm{mV}$ against an $\mathrm{Ag} / \mathrm{AgCl}$ reference electrode. A standard curve generated by the measurement of four reference standards was used to calculate the amounts of 5-HT and 5-HIAA per injection. Using these values the amount of 5-HT and 5-HIAA per dialysate sample was calculated. The detection limit for both 5-HT and 5-HIAA at a signal-to-noise ratio of 3 was $0.5 \mathrm{fmol}$ per injection.

A radioimmunoassay (ICN Biomedicals, Costa Mesa, CA, USA) was used to measure corticosterone in dialysates (detection limit $0.001 \mu \mathrm{g} / 100 \mathrm{ml}$ ) as described previously (Linthorst et al, 1994, 1995).

\section{Histology}

The mice were killed, after completion of experimental day 2 , by an overdose of pentobarbital. Brains were stored in a $4 \%$ formalin solution. The neuroanatomical localization of the microdialysis probe was histologically verified as described before (Linthorst et al, 1995). Only data from mice with correctly placed microdialysis probes were included in the analyses.

\section{Materials}

NBI 30775 was a gift from Janssen Pharmaceutica (Beerse, Belgium). All other chemicals used (analytical or HPLC grade) were purchased from Merck (Darmstadt, Germany) or Sigma-Aldrich Chemie GmbH (Taufkirchen, Germany).

\section{Statistics}

Data are expressed as mean \pm SEM. Owing to the different sample durations -30 and $60 \mathrm{~min}$ for the diurnal rhythm, and 15 and $10 \mathrm{~min}$ for the swim experiment -5 -HT and 5HIAA levels were expressed as $\mathrm{fmol} / \mathrm{min}$.

To estimate the effects of treatment (between-subject factor) and time (within-subject factor) on 5-HT, 5-HIAA, free corticosterone, and behavioral activity over the diurnal rhythm, analyses of variance (ANOVAs) were performed. All data used in the ANOVAs were natural logarithmictransformed (or in the case of behavioral activity, arcsinetransformed) before to approach the criteria of homogeneity and normality. To reduce the number of tests and therewith the probability of type 1 errors, the number of levels of the factor time was decreased by averaging values over 3-h periods (resulting in eight levels). A similar procedure has been published for the analysis of mouse and rat microdialysis data by our group before (Peñalva et al, 2002; Linthorst et al, 2002). To analyze the effects of forced swimming on hippocampal 5-HT and 5-HIAA, levels were expressed as percentage of baseline (baseline is defined as the average level of 5-HT and 5-HIAA in samples during which the animal was $\leqslant 10 \%$ of the sample duration behaviorally active; see also Peñalva et al, 2002). The effects of swim stress on 5-HT, 5-HIAA, free corticosterone, and behavioral activity were statistically evaluated by ANOVA with time as the within-subject factor and treatment as the between-subject factor. Also in this case, the number of levels for the within-subject factor time was reduced by averaging data into one baseline (8 values), one stress (1 value), and three poststress ( 4,4 , and 8 values, respectively) levels. Analyses using the means over distinct time periods yielded similar results as those including all time points (data not shown). If a significant interaction effect between two factors or a significant main effect for a factor was found in the ANOVA, post hoc tests with contrasts were performed to locate the differences between the factor levels exactly.

The effects of NBI 30775 on the area under the curve (AUC) of the stress-induced responses in 5-HT, 5-HIAA, and free corticosterone were statistically tested with Student's $t$-test. The effects of treatment with NBI 30775 on the intake of liquid diet and body weight gain were statistically evaluated using Student's $t$-test and ANOVA (with treatment as the between-subject factor and time as the within-subject factor), respectively. The consequences of chronic administration of NBI 30775 for behavior during forced swimming were analyzed with Student's $t$-tests.

$P<0.05$ was accepted as the level of significance. It was reduced according to the Bonferroni procedure for the post hoc contrasts to keep the probability of a type 1 error $<5 \%$. For the sake of clarity, the effect of the factors and their interactions (ANOVAs) are described in the text only.

\section{RESULTS}

\section{Intake of NBI 30775 and Effect on Body Weight}

Control mice $(n=22)$ consumed $14.2 \pm 0.2 \mathrm{ml}$ of the liquid diet daily. The intake of $14.3 \pm 0.2 \mathrm{ml}$ liquid diet in the NBI 30775 -treated $(n=20)$ group $(P>0.05$ as compared to control) resulted in a daily dose of $18.9 \pm 0.4 \mathrm{mg}$ NBI $30775 /$ $\mathrm{kg}$ body weight. The long-term treatment with NBI 30775 had no effect on body weight (control group $(n=22)$ : start weight: $25.2 \pm 0.3 \mathrm{~g}$, weight at the day of insertion of the probe: $26.6 \pm 0.4 \mathrm{~g}$; NBI 30775 -treated group $(n=20)$ : start weight: $25.2 \pm 0.4 \mathrm{~g}$, weight at the day of insertion of the probe (= day 13 of treatment): $27.4 \pm 0.6 \mathrm{~g} ; P>0.05$ ).

\section{Effects of NBI 30775 on the Diurnal Rhythms of Free Corticosterone, Hippocampal 5-HT and 5-HIAA, and Behavioral Activity}

Free corticosterone in dialysates showed a clear diurnal rhythm with low levels during the morning hours of the light phase and a marked increase starting at about 1300 (effect of time $\mathrm{F}(7,140)=87.1, P<0.0001$; Figure 1a). Maximum concentrations were reached at the onset of the dark period, after which a rapid return to levels similar to early morning levels within $60-90 \mathrm{~min}$ was observed. Free corticosterone continued to be low during the rest of the dark period. Long-term treatment of mice with NBI 30775 had no significant effect on the diurnal rhythm of free corticosterone (effect of treatment $\mathrm{F}(1,20)=2.9, P>0.05$; interaction between treatment and time $\mathrm{F}(7,140)=0.3$, $P>0.05$; Figure 1a).

Hippocampal extracellular concentrations of 5-HT and its metabolite 5-HIAA also showed a clear diurnal rhythm with 
higher levels during the dark as compared to the light phase of the light-dark cycle (effect of time: 5 - $\mathrm{HT} \mathrm{F}(7,63)=4.1$, $P=0.001$; 5-HIAA $\mathrm{F}(7,77)=19.9, P<0.0001$; Figures $1 \mathrm{~b}, \mathrm{c})$. Long-term treatment with NBI 30775, however, did not significantly affect the diurnal rhythms of 5-HT and 5-HIAA (effect of treatment: 5-HT $\mathrm{F}(1,9)=3.1, P>0.05$; 5-HIAA
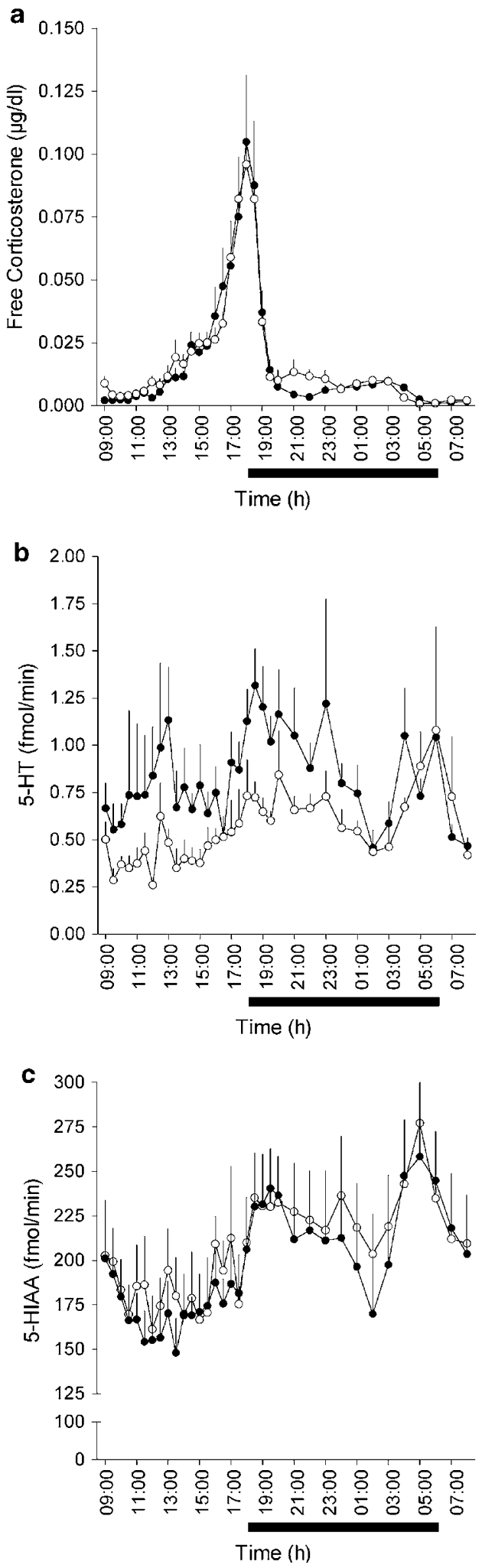

$\mathrm{F}(1,11)=0.1, P>0.05$; interaction between treatment and time: 5-HT $\mathrm{F}(7,63)=0.6, P>0.05 ; 5$-HIAA $\mathrm{F}(7,77)=0.9$, $P>0.05$; Figures $1 \mathrm{~b}, \mathrm{c})$.

Behavioral activity in the home cage was scored between 0900 and 2300. Whereas the mice also showed some behavioral activity during the light period, a profound increase in activity was observed at the onset of the dark phase. NBI 30775 had, however, no effect on the diurnal rhythm of behavioral activity (effect of time: $\mathrm{F}(4,44)=41.2$, $P<0.0001$; effect of treatment: $\mathrm{F}(1,11)=2.0, \quad P>0.05$; interaction between treatment and time $\mathrm{F}(4,44)=1.6$, $P>0.05$; see Table 1 for mean behavioral activity during the light and the dark phase). Moreover, we have found no indication for a change in the pattern of behavior displayed in the home cage by NBI 30775 (data not shown).

\section{Effect of NBI 30775 on Behavior during and after Forced Swimming}

Mice showed a characteristic behavioral pattern during forced swimming (Table 2). During the first 1-2 min, the animals struggled and tried to escape from the glass beaker by making climbing movements against the wall. Then, animals were mainly floating (about $50 \%$ of the total time of the forced swim period) alternated with short periods of swimming (about $30 \%$ of the total time of the forced swim period). Long-term treatment with NBI 30775 had no significant effect on the behaviors displayed during forced swimming (Table 2).

Table I Effect of Chronic Treatment with the $\mathrm{CRH}-\mathrm{RI}$ Antagonist NBI 30775 on Behavior in the Home Cage in C57BI/6N Mice Under Basal Conditions and After Forced Swim Stress

\begin{tabular}{lcc}
\hline Parameter & Control group & NBI 30775 group \\
\hline $\begin{array}{l}\text { Mean behavioral activity during } \\
\text { the light phase (counts/h) }\end{array}$ & $16.3 \pm 1.0, n=6$ & $15.9 \pm 0.9, n=7$ \\
$\begin{array}{l}\text { Mean behavioral activity during } \\
\text { the dark phase (counts/h) }\end{array}$ & $37.4 \pm 1.6, n=6$ & $43.5 \pm 3.3, n=7$ \\
$\begin{array}{l}\text { Behavioral activity during the first } \\
60 \text { min after swim stress (counts) }\end{array}$ & $84.9 \pm 10.6, n=7$ & $80.2 \pm 5.2, n=6$ \\
$\begin{array}{l}\text { Grooming during the first } 60 \text { min } \\
\text { after swim stress (counts) }\end{array}$ & $46.6 \pm 3.3, n=7$ & $45.1 \pm 1.9, n=6$ \\
\end{tabular}

Behavioral activity and grooming were scored from video tape in I min (first experimental day, diurnal rhythm) and 30 s (second experimental day, postswim stress) intervals. Maximal number of counts are 60 and 120 counts/h for diurnal and postswim stress behavior, respectively. Data represent mean \pm SEM. For results of the ANOVA analyses on the time courses, see Results.

Figure I Effects of chronic treatment with the $\mathrm{CRH}-\mathrm{RI}$ antagonist NB 30775 (filled circles) on free corticosterone ( $\mu \mathrm{g} / \mathrm{dl} ; \mathrm{a})$, and hippocampal extracellular levels of 5-HT and 5-HIAA (fmol/min; b and c) in C57BI/6N mice during the light-dark cycle (first experimental day, I5 days of treatment, see Methods and materials). Control animals are represented by the open circles. Microdialysates were collected in 30-min (0900-2000) and 60-min (2000-0900) intervals. The time points on the $x$-axis correspond to the time of the day at which collection of the microdialysis sample was started. The black bar indicates the dark phase of the light-dark cycle (1800-0600). Values represent mean + SEM (control group: $n=10$, 5, 6; NBI 30775 group: $n=12,6,7$ for figures $a, b$ and c, respectively). For results of the ANOVA analyses, see Results. 
Table 2 Effect of Chronic Treatment with the $\mathrm{CRH}-\mathrm{RI}$ Antagonist NBI 30775 on Behaviors Performed During Forced Swimming in $\mathrm{C} 57 \mathrm{Bl} / 6 \mathrm{~N}$ Mice

\begin{tabular}{lcc}
\hline $\begin{array}{l}\text { Behavior } \\
\text { (\% of total number of counts) }\end{array}$ & $\begin{array}{c}\text { Control } \\
\text { group }\end{array}$ & $\begin{array}{c}\text { NBI } \mathbf{3 0 7 7 5} \\
\text { group }\end{array}$ \\
\hline Climbing/struggling & $16.2 \pm 1.8$ & $15.7 \pm 2.0$ \\
Swimming & $29.4 \pm 4.5$ & $29.5 \pm 4.3$ \\
Floating & $54.4 \pm 4.9$ & $54.8 \pm 4.8$ \\
\hline
\end{tabular}

Mice were forced to swim for 10 min in water of $25^{\circ} \mathrm{C}$ on the second experimental day ( 16 days of treatment, see Methods and materials). Behaviors were scored from video tape in 5-s intervals and are expressed as \% of total number of counts. Data represent mean \pm SEM (control group: $n=|5 ; \mathrm{NB}|$ 30775 group: $n=12$ )

After the forced swimming period, mice were dried with tissue paper and returned to their home cage. During the first 30-45 min after swimming, mice were mainly grooming to dry their fur. No effects of NBI 30775 on poststress behavioral activity were observed (effect of treatment on total behavioral activity $\mathrm{F}(1,11)=0.2, P>0.05$; on grooming $\mathrm{F}(1,11)=0.7, P>0.05$; see Table 1 for number of counts for behavioral activity and grooming during the first $60 \mathrm{~min}$ after swim stress).

\section{Effects of NBI 30775 on Forced Swimming-Induced Changes in Free Corticosterone and Hippocampal 5-HT and 5-HIAA}

Forced swimming for $10 \mathrm{~min}$ in water of $25^{\circ} \mathrm{C}$ is clearly a stressful experience for mice, as indicated by the profound increase in free corticosterone (effect of time: $\mathrm{F}(4,48)=52.9$, $P<0.0001$; Figure 2a). Free corticosterone levels were significantly elevated as compared to baseline in the first sample and reached a maximum in the second sample after termination of forced swim stress (between 10-25 and 25$40 \mathrm{~min}$ after the onset of swimming, respectively). Then free

Figure 2 Effects of chronic treatment with the $\mathrm{CRH}-\mathrm{RI}$ antagonist NBI 30775 (filled circles) on forced swim stress-induced changes in free corticosterone ( $\mu \mathrm{g} / \mathrm{dl} ; \mathrm{a})$, and hippocampal extracellular levels of 5-HT and 5-HIAA (\% of baseline; $b$ and $c$ ) in C57BI/6N mice (second experimental day, 16 days of treatment, see Methods and materials). Control animals are represented by the open circles. After measurement of baseline $(0900$ I 100), mice were subjected to a 10-min forced swim stress (start 1100 , indicated by the arrow; water temperature $25^{\circ} \mathrm{C}$ ). Microdialysates were collected in 15-min intervals (except for the forced swim period: 10-min interval). The time points on the $x$-axis correspond to the time of the day at which collection of the microdialysis sample was started. The dashes on the $x$-axis indicate that after 10-min forced swim stress, samples were collected in 15-min intervals again. The variations in prestress values of 5HT and 5-HIAA are related to normal behavioral activity of the mice and were not statistically different between the two treatment groups. Baseline free corticosterone levels were around the detection limit of the assay $(0.00 \mathrm{I} \mu \mathrm{g} / \mathrm{dl})$ because only $30 \mu \mathrm{l}$ dialysate (I 5 -min sample) was available for the radioimmunoassay. Values represent mean + SEM (control group: $n=8,7,7 ; \mathrm{NBI} 30775$ group: $n=6,6,6$ for figures a, b, and c, respectively). *Significant difference between control- and NBI 30775-treated mice. ${ }_{P} P=0.04$ for the difference between control- and NBI 30775-treated mice. + Significantly different from baseline for control-treated mice. ${ }^{\text {\#Significantly }}$ different from baseline for NBI 30775-treated mice (all post hoc tests with contrasts and Bonferroni correction; see Methods and materials). For results of the ANOVA analyses, see Results. corticosterone concentrations started to decrease, returning to baseline levels about $2 \mathrm{~h}$ after the stressful experience. No difference in the swim stress-induced increase in free corticosterone between control- and NBI 30775-treated mice was observed (effect of treatment: $F(1,12)=1.0$, $P>0.05$; interaction between treatment and time: $\mathrm{F}(4,48)=1.7, \quad P>0.05$; Figure $2 \mathrm{a})$. This conclusion is
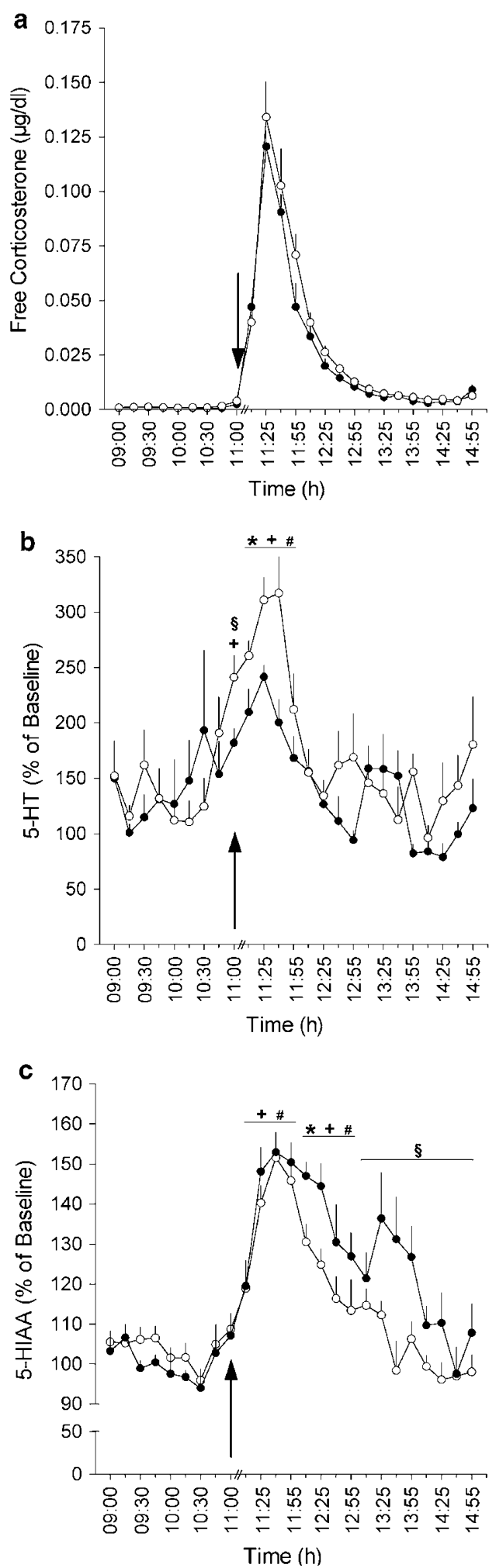

Neuropsychopharmacology 
underscored by the absence of NBI 30775-induced differences in the AUC of the free corticosterone response (AUC control group: $0.50 \pm 0.05$, AUC NBI 30775 group: $0.42 \pm 0.03 \mu \mathrm{g} / \mathrm{dl} \times$ sample number; $P>0.05)$.

Forced swimming caused an immediate increase in hippocampal levels of 5-HT in control mice (Figure 2b). After termination of the swim procedure, 5-HT levels continued to increase, reaching a maximum 15-30 min later. Then extracellular 5-HT concentration returned rapidly to baseline levels again. The swim stress-induced increase in hippocampal extracellular 5-HT was, however, significantly attenuated in NBI 30775-treated mice as compared to the control group (effect of treatment: $\mathrm{F}(1,11)=6.5, P<0.05$; AUC control group: $3035 \pm 153$, AUC NBI 30775 group: $2436 \pm 75 \%$ of baseline $\times$ sample number, $P<0.01$; Figure 2b). The forced swimming procedure also resulted in increased levels of hippocampal 5-HIAA reaching a peak between 30 and 45 min after completion of the stress procedure (Figure 2c). Control- and NBI 30775-treated mice showed no differences in the maximum effect of swimming on hippocampal 5-HIAA. However, the effect of swim stress on 5-HIAA was significantly more prolonged in NBI 30775-treated animals as compared to the control group (interaction between treatment and time: $\mathrm{F}(4,44)=4.1, P<0.01$; Figure $2 \mathrm{c}$ ). Thus, the AUC for the response of 5-HIAA to forced swimming was significantly higher in NBI 30775- as compared to control-treated mice (AUC control group: $1976 \pm 22$, AUC NBI 30775 group: $2164 \pm 73 \%$ of baseline $\times$ sample number, $P<0.05)$.

\section{DISCUSSION}

Hippocampal extracellular concentrations of 5-HT and 5HIAA show a clear diurnal rhythm with low levels during the light and elevated levels during the dark phase, the active period of rats and mice (Linthorst et al, 1994; Rueter and Jacobs, 1996; Peñalva et al, 2002). Chronic NBI 30775 treatment had no significant effect on the diurnal levels of 5HT and 5-HIAA in the hippocampus of $\mathrm{C} 57 \mathrm{Bl} / 6 \mathrm{~N}$ mice. This may indicate that CRH-R1 plays no major role in hippocampal serotonergic neurotransmission under baseline (diurnal) conditions. At present, it is, however, not clear yet whether $\mathrm{CRH}$ itself represents an important mediator in the regulation of the diurnal rhythm of serotonergic neurotransmission. Recently, we reported that i.c.v. treatment with the nonspecific CRH-R antagonist DPhe- $\mathrm{CRH}_{12-41}$ reduces hippocampal 5-HT in resting rats during the light period (Linthorst et al, 2002). Moreover, intraperitoneal administration of the CRH-R1 antagonist CP-154,526 lowers dialysate levels of $5-\mathrm{HT}$ in the rat hippocampus (Isogawa et al, 2000). These effects are, however, relatively small (about 20\%), pointing to the involvement of other, more prominent, regulators of diurnal hippocampal serotonergic neurotransmission.

There is now substantial neuroanatomical evidence for interactions between $\mathrm{CRH}$ and serotonin at the level of the raphe nuclei. $\mathrm{CRH}$ immunoreactivity has been shown in the dorsal and median raphe nucleus (Sakanaka et al, 1987; Swanson et al, 1983; Ruggiero et al, 1999; Kirby et al, 2000; Lowry et al, 2000; Valentino et al, 2001). CRH-R1 and
CRH-R2 mRNA has been found in the raphe nuclei (Chalmers et al, 1995; Bittencourt and Sawchenko, 2000; Van Pett et al, 2000) and, importantly, a recent doublelabeling immunohistochemistry study demonstrates that tryptophan-hydroxylase immunoreactive neurons in the dorsal raphe nucleus also express $\mathrm{CRH}-\mathrm{R} 1$ immunoreactivity (Lowry et al, 2002). Interestingly, CRH-R immunoreactivity has also been described in GABAergic neurons in the dorsal raphe nucleus (Roche et al, 2003). These observations put $\mathrm{CRH}$ in a unique position to regulate or modulate serotonergic responses to stress (directly or indirectly by influencing GABA neurotransmission). Indeed, it has been shown that administration of CRH (and Ucn) changes the discharge rate of 5-HT neurons (Kirby et al, 2000; Lowry et al, 2000) and the extracellular levels of 5 -HT in the projection areas (Price et al, 1998; Price and Lucki, 2001; Linthorst et al, 2002), albeit in a neuroanatomical and dose-specific manner. Stress also causes brain region- and stressor-specific changes in serotonin levels (see Chaouloff, 2000). However, only few studies have attempted to assess the role of $\mathrm{CRH}$ and its receptors in stress-induced alterations in 5-HT. Recently, we have found a pronounced increase in hippocampal 5-HT levels in rats that dived during a forced swim stress paradigm. This effect depended on CRH-R, because it could be prevented by i.c.v. pretreatment of the animals with the $\mathrm{CRH}-\mathrm{R}$ antagonist $\mathrm{D}$ Phe- $\mathrm{CRH}_{12-41}$ (Linthorst et al, 2002). D-Phe-CRH $\mathrm{CH}_{12-41}$ also blocks swim stress-induced decreases in extracellular levels of 5-HT in the lateral septum of rats (Price et al, 2002). In contrast, no role of $\mathrm{CRH}$ has been found in foot shock stress-induced changes in 5-HT turnover (Dunn, 2000). In this study, we investigated the effect of chronic blockade of CRH-R1 with the antagonist NBI 30775 on swim stressinduced changes in hippocampal 5-HT. Forced swim stress at $25^{\circ} \mathrm{C}$ increases hippocampal extracellular 5-HT levels in mice (in this study and Peñalva et al, 2002), and in rats (Linthorst et al, 2002). NBI 30775 caused a significantly attenuated swim stress-induced increase in hippocampal 5$\mathrm{HT}$, indicating that stimulation of CRH-R1 may be necessary for an appropriate 5-HT response to swim stress. The forced swimming-induced maximum increase in hippocampal levels of the metabolite 5-HIAA was similar in control- and NBI 30775-treated mice. The antagonist group, however, showed a markedly prolonged poststress elevation of 5-HIAA levels as compared to the control group. This is an intriguing observation for several reasons: first, it shows that CRH-R1 may also play a role in stressinduced alterations in the metabolism of 5-HT. At present, the significance of extracellular levels of 5-HIAA is not yet fully resolved. Evidence has been accumulating showing that 5-HIAA levels in dialysates do not reflect the metabolism of 5-HT previously being released (Auerbach et al, 1989; Crespi et al, 1990; Wright et al, 1992; Linthorst et al, 1994, Rueter et al, 1997). Instead, extracellular 5-HIAA seems to be largely derived from metabolism of the spillover of newly synthesized, yet unreleased 5-HT, and hence may be regarded as an index for the level of synthesis of 5-HT within serotonergic neurons (see Grahame-Smith, 1974; Kuhn et al, 1986). Thus, the prolonged increase in 5-HIAA in NBI 30775-treated animals may point to an enhanced poststress synthesis of 5 -HT during chronic CRH-R1 blockade. Second, given the postulate that hypoactivity of 
the 5-HT system plays a key role in the etiology of major depression, this observation suggests that NBI 30775 could exert its therapeutical efficacy by preparing the 5-HT system for subsequent stressors by an enhancement of poststress synthesis of the neurotransmitter. The data presented here represent first evidence for altered responses of hippocampal serotonergic neurotransmission to stress after chronic treatment with a new compound with potential antidepressant and anxiolytic properties in humans. Comprehensive and systematic studies also implementing chronic treatment regimes with antidepressant drugs of other chemical classes affecting the 5-HT system (SSRIs, monoamine oxidase A inhibitors and the selective 5-HT reuptake enhancer tianeptine) are, however, urgently needed to clarify further the significance of alterations in the stress-responsiveness of 5-HT for the treatment of depression and/or anxiety. Importantly, such studies should also include a comparison between the effects of chronic administration of CRH-R1 antagonists and 'classical' antidepressants at the postsynaptic (5-HT receptors, second messengers) level. The exact neuroanatomical localization of the effects of NBI 30775 on stress-induced changes in serotonergic neurotransmission is still unclear. However, based on the presence of $\mathrm{CRH}$ fibers in the raphe nuclei (see above) and the recent description of CRH-R1-immunoreactivity in 5-HT neurons (Lowry et al, 2002) and of CRH-R-immunoreactivity in GABAergic interneurons in the dorsal raphe nucleus (Roche et al, 2003), it may be speculated that the effects of NBI 30775 are generated at the level of the raphe nuclei.

The present observations regarding serotonergic neurotransmission are in contrast with our findings in CRH-R1deficient mice (Peñalva et al, 2002). In these mutant mice, hippocampal extracellular levels of 5-HIAA, but not of 5HT, are elevated over the whole diurnal rhythm as compared to wild-type and heterozygous animals. Moreover, CRH-R1-deficient homozygous and heterozygous mice show an enhanced hippocampal 5-HT, but a normal 5-HIAA response, to forced swim stress. The discrepancies between a genetic and a pharmacological model of longterm reduction of CRH-R1 function may be related to differences at the level of the HPA axis (see also below). Whereas the diurnal rhythm of free corticosterone levels is normal in NBI 30775-treated mice, CRH-R1 mutant mice show undetectable levels of total plasma corticosterone (Timpl et al, 1998; Smith et al, 1998) and brain free corticosterone (Peñalva et al, 2002). There is now, mainly electrophysiological, evidence showing that glucocorticoids may play a role in the regulation of serotonergic neurotransmission (Laaris et al, 1995). Adrenalectomy, however, exerts no major effects on the firing rate of 5-HT neurons (Laaris et al, 1995) and on tryptophan hydroxylase activity (Singh et al, 1990; Sze et al, 1976; Kizer et al, 1976) under basal conditions. Moreover, hippocampal extracellular levels of 5-HT and 5-HIAA are unchanged under resting (and CRH-stimulated) conditions in adrenalectomized rats (Linthorst et al, 2002). Hence, based on the present evidence, the discrepant results between CRH-R1 antagonist-treated and CRH-R1-deficient mice cannot be satisfactorily explained by changes at the level of HPA axis hormones. Furthermore, it cannot be excluded, that life-long CRH-R1-deficiency may have caused compensatory mechanisms differing from those elicited by pharmacological CRH-R1 blockade for 15 days, for instance involving CRH-R2 or $\mathrm{CRH} / \mathrm{Ucn}$ (see also discussion in Peñalva et al, 2002).

Originally, forced swimming was selected as a stressor in our experiments, as it has been repeatedly demonstrated to be a strong activator of the HPA axis and hippocampal serotonergic neurotransmission (Timpl et al, 1998; Peñalva et al, 2002; Linthorst et al, 2002). Nevertheless, given the principal role of the hippocampus in stress-related behavior and the widespread use of the Porsolt forced swim test in rats for the screening of drugs with putative antidepressant potential, analysis of the behavior during and after the forced swim paradigm could be of interest. In the Porsolt forced swim test, putative antidepressant substances cause, after repeated (three times) acute injection, reduced immobility in a swim retest situation (Porsolt et al, 1977b). The test has also been adapted for mice using only one swim session (Porsolt et al, 1977a). However, there is some doubt as to whether the classical Porsolt swim test can reliably detect putative antidepressants from all chemical classes, for instance from the selective serotonin reuptake inhibitors (Cryan et al, 2002) or reversible MAO-A inhibitors (Montkowski et al, 1995). To overcome this problem, Lucki and coworkers introduced and validated a modified forced swim test in the rat with an alternative scoring paradigm implementing two active behaviors, that is, climbing and swimming behavior (Detke et al, 1995; Cryan et al, 2002). The enhanced sensitivity of the rat modified forced swim test allows the detection of antidepressant properties of drugs directed to interfere with norepinephrine and serotonin. Here, we have adopted the scoring paradigm of the rat-modified test for use in mice, although it should be noted that the animals were chronically and not acutely treated with NBI 30775, and only one swim session was performed. Chronic treatment with NBI 30775 did not result in changes in climbing and swimming behavior displayed during forced swim stress, despite the reduced responsiveness of hippocampal 5-HT. Moreover, there was no significant effect of NBI 30775 on the amount of immobility (during the total $15 \mathrm{~min}$ of swimming), and also not when immobility was scored according to the classical mouse Porsolt paradigm (ie scoring during the last $4 \mathrm{~min}$ of a 6 -min swim session; data not shown). In line with this observation, acute administration of the nonselective CRH-R antagonist alpha-helicalCRH has no effect on immobility in rats during a first and second swim session (Garcia-Lecumberri and Ambrosio, 1998). In contrast, the CRH-R1 antagonist SSR125543A shows antidepressant characteristics in the standard rat Porsolt forced swim test (Griebel et al, 2002). The reasons for the absence of antidepressant properties of NBI 30775 in our study are not clear. A very low dose of the drug is not likely to be the cause, because the dose used in this study, as well as lower doses, have been reported to exert anxiolytic effects in various tests in rats (Keck et al, 2001; Heinrichs et al, 2002; Gutman et al, 2003). Moreover, as indicated by the changes in serotonergic neurotransmission reported here, NBI 30775 shows biological activity not only in rats but also in mice. This notion is further underlined by the observation that acute oral administration of NBI 30775 in mice induces selective anxiolytic effects, without changing locomotor activity, as indicated by a decreased avoidance 
towards an unprotected area in the modified hole board task (personal communication: Dr Frauke Ohl, Max Planck Institute of Psychiatry, Munich). It can be argued that the selected treatment regimen, that is, oral administration of NBI 30775 via the food, may underlie the absence of behavioral and neuroendocrine (see below) effects in the present study. However, treatment regimens in which drugs have been added to the drinking water or food have successfully been used to demonstrate the effects of various antidepressants on HPA axis regulation (see Reul et al, 1993, 1994; Bachmann et al, 2003). Although we did not study receptor occupation after chronic treatment with NBI 30775 , a recent report by Gutman et al (2003) shows that even $8 \mathrm{~h}$ after acute intravenous administration of NBI 30775 (10 mg/kg body weight), $45 \%$ of CRH-R1 in the rat frontal cortex are still occupied by the antagonist. Moreover, binding of NBI 30775 to CRH-R1 was found to be dose-dependent. As a two-fold higher dose was administered in the present study and because clear effects on hippocampal serotonergic neurotransmission were found, we anticipate that a substantial number of CRH-R1 is occupied. Alternatively, it cannot be excluded that the forced swim test (standard or modified) in mice is not an appropriate paradigm for the screening of antidepressant potential of drugs interacting with the $\mathrm{CRH}$ system. Moreover, it should be emphasized that data on the validity of the forced swim test during chronic treatment paradigms are still limited. Nevertheless, our data suggest that hippocampal 5-HT is not a principal mediator of the behaviors displayed during forced swim stress.

Whereas CRH-R1 antagonists blunt stress-induced increases in plasma ACTH and corticosterone after acute administration (Arborelius et al, 2000; Keck et al, 2001; Heinrichs et al, 2002; Gutman et al, 2003), chronic oral treatment with NBI 30775 had no consequences for HPA axis functioning. As compared to the control group, NBI 30775-treated mice showed a normal diurnal rhythm of free corticosterone and a similar response to swim stress. In accordance with these observations, Gutman et al (2003) recently reported that acute intravenous administration of NBI 30775 has no effects on basal plasma levels of ACTH and corticosterone in rats. Also in depressed patients, chronic oral treatment with NBI 30775, at dosages which have CNS effects, did not affect the HPA axis, as indicated by normal baseline and CRH-induced levels of ACTH and cortisol (Zobel et al, 2000). In line with our findings, Arborelius et al (2000) showed that chronic treatment with the CRH-R1 antagonist CP-154,526 (subcutaneously via a miniosmotic pump) has no effect on basal plasma levels of $\mathrm{ACTH}$ and corticosterone in the rat. Moreover, airpuff startle induces a normal increase in ACTH and corticosterone (although the latter was somewhat prolonged) in CP154,526-treated animals (Arborelius et al, 2000). Chronic administration of the CP-154,526 analog antalarmin, by twice-daily intraperitoneal injection, also has no effects on stress (immobilization)-induced HPA axis activation (Wong et al, 1999), although baseline levels of ACTH and corticosterone were reduced after 11 days (Bornstein et al, 1998) and 8 weeks (Wong et al, 1999) of treatment. These observations are rather surprising, given the critical requirement of $\mathrm{CRH}-\mathrm{R} 1$ for HPA axis responses to stress (Timpl et al, 1998; Smith et al, 1998) and during the diurnal surge (Peñalva et al, 2002; see also Reul and Holsboer, 2002). Several explanations for the resistance of the HPA axis to chronic CRH-R1 antagonist administration may be considered. First, it cannot be excluded that the dose of NBI 30775 used $(18.4 \mathrm{mg} / \mathrm{kg} /$ day) does not block all CRH-R1 in mice. A recent study at our Institute shows that acute injection of $20 \mathrm{mg} / \mathrm{kg}$ NBI 30775 largely displaces ${ }^{125} \mathrm{I}$-oCRH binding to CRH-R1 in the brain of rats (Keck et al, 2001). This finding was confirmed by another study using ${ }^{125} \mathrm{I}-$ sauvagine binding (Heinrichs et al, 2002). However, with this dose, there may be a number of nonblocked CRH-R1 left at the level of the pituitary, sufficient to maintain normal HPA axis activity. The observation that acute injection of $20 \mathrm{mg} / \mathrm{kg}$ NBI 30775 in rats blunts, but not eliminates, stress-induced increases in ACTH and corticosterone (Keck et al, 2001; Heinrichs et al, 2002; Gutman et al, 2003) underscores this possibility. Second, because elevated levels of CRH are known to cause downregulation of CRH$\mathrm{R} 1$ in the pituitary, it may be postulated that chronic blockade of CRH-R1 by NBI 30775 causes adaptations in receptor number and/or postreceptor mechanisms (see Aguilera et al, 2001), possibly leading to a normalization of HPA axis performance. Third, compensatory mechanisms, for instance at the level of the ACTH secretagogue vasopressin, may have developed during the chronic treatment procedure. From a therapeutical point of view, the absence of a suppression of HPA axis activity by CRH$\mathrm{R} 1$ antagonists, aimed for the treatment of psychiatric disorders, may be a favorable feature. Compromising HPA axis responsiveness may namely cause detrimental complications during stressful situations in which glucocorticoids are mandatory, such as infection and injury.

In summary, this study shows that chronic oral treatment with the CRH-R1 antagonist NBI 30775 was well-tolerated by mice. NBI 30775 caused no changes in food intake, body weight, and HPA axis functioning, but resulted in complex changes in hippocampal serotonergic neurotransmission. The prolonged poststress elevation of 5-HIAA levels suggests that treatment with NBI 30775 leads to adaptive changes in serotonergic neurotransmission (putatively synthesis), which may contribute to the proposed therapeutical (antidepressant, anxiolytic) efficacy of this class of psychopharmacological substances.

\section{ACKNOWLEDGEMENTS}

We thank Dr Alexander Yassouridis for expert advice on the statistical analysis. We thank Ms Monika Mailinger for superb secretarial assistance. This study was supported by the Max Planck Society.

\section{REFERENCES}

Aguilera G, Rabadan-Diehl C, Nikodemova M (2001). Regulation of pituitary corticotropin releasing hormone receptors. Peptides 22: 769-774.

Arborelius L, Skelton KH, Thrivikraman KV, Plotsky PM, Schulz DW, Owens MJ (2000). Chronic administration of the selective corticotropin-releasing factor 1 receptor antagonist CP-154,526: behavioral, endocrine and neurochemical effects in the rat. $J$ Pharmacol Exp Ther 294: 588-597. 
Auerbach SB, Minzenberg MJ, Wilkinson LO (1989). Extracellular serotonin and 5-hydroxyindoleacetic acid in hypothalamus of the unanesthetized rat measured by in vivo dialysis coupled to high-performance liquid chromatography with electrochemical detection: dialysate serotonin reflects neuronal release. Brain Res 499: 281-290.

Bachmann CG, Linthorst ACE, Holsboer F, Reul JMHM (2003). Effect of chronic administration of selective glucocorticoid receptor antagonists on the rat hypothalamic-pituitary-adrenalcortical axis. Neuropsychopharmacology 28: 1056-1067.

Bittencourt JC, Sawchenko PE (2000). Do centrally administered neuropeptides access cognate receptors? An analysis in the central corticotropin-releasing factor system. J Neurosci 20: 1142-1156.

Bornstein SR, Webster EL, Torpy DJ, Richman SJ, Mitsiades N, Igel $\mathrm{M}$ et al (1998). Chronic effects of a nonpeptide corticotropinreleasing hormone type I receptor antagonist on pituitaryadrenal function, body weight, and metabolic regulation. Endocrinology 139: 1546-1555.

Carroll BJ, Feinberg M, Greden JF, Tarika J, Albala AA, Haskett RF et al (1981). A specific laboratory test for the diagnosis of melancholia. Standardization, validation, and clinical utility. Arch Gen Psychiatry 38: 15-22.

Chalmers DT, Lovenberg TW, De Souza EB (1995). Localization of novel corticotropin-releasing factor receptor $\left(\mathrm{CRF}_{2}\right)$ mRNA expression to specific subcortical nuclei in rat brain: comparison with $\mathrm{CRF}_{1}$ receptor mRNA expression. J Neurosci 15: 6340-6350.

Chaouloff F (2000). Serotonin, stress and corticoids. J Psychopharmacol 14: 139-151.

Crespi F, Garratt JC, Sleight AJ, Marsden CA (1990). In vivo evidence that 5-hydroxytryptamine $(5-\mathrm{HT})$ neuronal firing and release are not necessarily correlated with 5-HT metabolism. Neuroscience 35: 139-144.

Cryan JF, Markou A, Lucki I (2002). Assessing antidepressant activity in rodents: recent developments and future needs. Trends Pharmacol Sci 23: 238-245.

Deak T, Nguyen KT, Ehrlich AL, Watkins LR, Spencer RL, Maier SF et al (1999). The impact of the nonpeptide corticotropinreleasing hormone antagonist antalarmin on behavioral and endocrine responses to stress. Endocrinology 140: 79-86.

Detke MJ, Rickels M, Lucki I (1995). Active behaviors in the rat forced swimming test differentially produced by serotonergic and noradrenergic antidepressants. Psychopharmacology 121: 66-72.

Deuschle M, Schweiger U, Weber B, Gotthardt U, Korner A, Schmider J et al (1997). Diurnal activity and pulsatility of the hypothalamus-pituitary-adrenal system in male depressed patients and healthy controls. J Clin Endocrinol Metab 82: 234-238.

Dunn AJ (2000). Footshock-induced changes in brain catecholamines and indoleamines are not mediated by CRF or ACTH. Neurochem Int 37: 61-69.

Garcia-Lecumberri C, Ambrosio E (1998). Role of corticotropinreleasing factor in forced swimming test. Eur J Pharm 343: $17-26$.

Grahame-Smith DG (1974). How important is the synthesis of brain 5-hydroxytryptamine in the physiological control of its central function? Adv Biochem Psychopharmacol 10: 83-91.

Griebel G, Perrault G, Sanger DJ (1998). Characterization of the behavioral profile of the non-peptide CRF receptor antagonist CP-154,526 in anxiety models in rodents. Comparison with diazepam and buspirone. Psychopharmacology 138: 55-66.

Griebel G, Simiand J, Steinberg R, Jung M, Gully D, Roger P et al (2002). 4-(2-Chloro-4-methoxy-5-methylphenyl)- $N$-[(1S)-2-cyclopropyl-1-(3-fluoro-4-methylphenyl)ethyl]5-methyl- $N$-(2-propynyl)-1,3-thiazol-2-amine hydrochloride (SSR125543A), a potent and selective corticotrophin-releasing factor(1) receptor antagonist. II. Characterization in rodent models of stressrelated disorders. J Pharmacol Exp Ther 301: 333-345.

Gutman DA, Owens MJ, Skelton KH, Thrivikraman KV, Nemeroff CB (2003). The corticotropin-releasing factor ${ }_{1}$ receptor antagonist R121919 attenuates the behavioral and endocrine responses to stress. J Pharmacol Exp Ther 304: 874-880.

Heinrichs SC, De Souza EB, Schulteis G, Lapsansky JL, Grigoriadis DE (2002). Brain penetrance, receptor occupancy and antistress in vivo efficacy of a small molecule corticotropin releasing factor type I receptor selective antagonist. Neuropsychopharmacology 27: 194-202.

Holsboer F (1999). The rationale for corticotropin-releasing hormone receptor (CRH-R) antagonists to treat depression and anxiety. J Psychiatr Res 33: 181-214.

Isogawa $\mathrm{K}$, Akiyoshi J, Hikichi $\mathrm{T}$, Yamamoto $\mathrm{Y}$, Tsutsumi $\mathrm{T}$, Nagayama H (2000). Effect of corticotropin releasing factor receptor 1 antagonist on extracellular norepinephrine, dopamine and serotonin in hippocampus and prefrontal cortex of rats in vivo. Neuropeptides 34: 234-239.

Keck ME, Welt T, Wigger A, Renner U, Engelmann M, Holsboer F et al (2001). The anxiolytic effect of the $\mathrm{CRH}(1)$ receptor antagonist R121919 depends on innate emotionality in rats. Eur J Neurosci 13: 373-380.

Kirby LG, Rice KC, Valentino RJ (2000). Effects of corticotropinreleasing factor on neuronal activity in the serotonergic dorsal raphe nucleus. Neuropsychopharmacology 22: 148-162.

Kizer JS, Palkovits M, Kopin IJ, Saavedra JM, Brownstein MJ (1976). Lack of effect of various endocrine manipulations on tryptophan hydroxylase activity of individual nuclei of the hypothalamus, limbic system, and midbrain of the rat. Endocrinology 98: 743-747.

Kuhn DM, Wolf WA, Youdim MB (1986). Serotonin neurochemistry revisited: a new look at some old axioms. Neurochem Int 8: 141-154.

Laaris N, Hajdahmane S, Hamon M, Lanfumey L (1995). Glucocorticoid receptor-mediated inhibition by corticosterone of 5-HT1A autoreceptor functioning in the rat dorsal raphe nucleus. Neuropharmacology 34: 1201-1210.

Linkowski P, Mendlewicz J, Leclercq R, Brasseur M, Hubain P, Golstein J et al (1985). The 24-h profile of adrenocorticotropin and cortisol in major depressive illness. J Clin Endocrinol Metab 61: 429-438.

Linthorst ACE, Flachskamm C, Barden N, Holsboer F, Reul JMHM (2000). Glucocorticoid receptor impairment alters CNS responses to a psychological stressor: an in vivo microdialysis study in transgenic mice. Eur J Neurosci 12: 283-291.

Linthorst ACE, Flachskamm C, Holsboer F, Reul JMHM (1994). Local administration of recombinant human interleukin-1 beta in the rat hippocampus increases serotonergic neurotransmission, hypothalamic-pituitary-adrenocortical axis activity, and body temperature. Endocrinology 135: 520-532.

Linthorst ACE, Flachskamm C, Hopkins SJ, Hoadley ME, Labeur MS, Holsboer F et al (1997). Long-term intracerebroventricular infusion of corticotropin-releasing hormone alters neuroendocrine, neurochemical, autonomic, behavioral, and cytokine responses to a systemic inflammatory challenge. J Neurosci 17: $4448-4460$.

Linthorst ACE, Flachskamm C, Müller-Preuss P, Holsboer F, Reul JMHM (1995). Effect of bacterial endotoxin and interleukin-1 beta on hippocampal serotonergic neurotransmission, behavioral activity, and free corticosterone levels: an in vivo microdialysis study. J Neurosci 15: 2920-2934.

Linthorst ACE, Karanth S, Barden N, Holsboer F, Reul JMHM (1999). Impaired glucocorticoid receptor function evolves in aberrant physiological responses to bacterial endotoxin. Eur J Neurosci 11: 178-186.

Linthorst ACE, Peñalva RG, Flachskamm C, Holsboer F, Reul JMHM (2002). Forced swim stress activates rat hippocampal 
serotonergic neurotransmission involving a corticotropin-releasing hormone receptor-dependent mechanism. Eur J Neurosci 16: 2441-2452.

Lowry CA, Johnson PL, Hathway NJA, Lightman SL (2002). Distribution of corticotropin-releasing factor receptor 1(CRFR1) and CRFR2-immunoreactivity in limbic and caudal brainstem raphe nuclei. Program No 86762002 Abstract Viewer/Itinerary Planner Washington, DC: Society for Neuroscience, $2002 \mathrm{CD}$-ROM.

Lowry CA, Rodda JE, Lightman SL, Ingram CD (2000). Corticotropin-releasing factor increases in vitro firing rates of serotonergic neurons in the rat dorsal raphe nucleus: evidence for activation of a topographically organized mesolimbocortical serotonergic system. J Neurosci 20: 7728-7736.

Lundkvist J, Chai Z, Teheranian R, Hasanvan H, Bartfai T, Jenck F et al (1996). A non peptidic corticotropin releasing factor receptor antagonist attenuates fever and exhibits anxiolytic-like activity. Eur J Pharmacol 309: 195-200.

Maes M, Meltzer HY (1995). The serotonin hypothesis of major depression. In: Bloom FE, Kupfer DJ (eds) Psychopharmacology: The Fourth Generation of Progress pp 933-944.

Millan MJ, Brocco M, Gobert A, Dorey G, Casara P, Dekeyne A (2001). Anxiolytic properties of the selective, non-peptidergic CRF(1) antagonists, CP154,526 and DMP695: a comparison to other classes of anxiolytic agent. Neuropsychopharmacology 25: $585-600$.

Montkowski A, Barden N, Wotjak C, Stec I, Ganster J, Meaney M et al (1995). Long-term antidepressant treatment reduces behavioural deficits in transgenic mice with impaired glucocorticoid receptor function. J Neuroendocrinol 7: 841-845.

Nemeroff CB (1996). The corticotropin-releasing factor (CRF) hypothesis of depression: new findings and new directions. $\mathrm{Mol}$ Psychiatry 1: 336-342.

Nemeroff CB, Owens MJ, Bissette G, Andorn AC, Stanley M (1988). Reduced corticotropin releasing factor binding sites in the frontal cortex of suicide victims. Arch Gen Psychiatry 45: 577-579.

Nemeroff CB, Widerlov E, Bissette G, Walleus H, Karlsson I, Eklund $\mathrm{K}$ et al (1984). Elevated concentrations of CSF corticotropin-releasing factor-like immunoreactivity in depressed patients. Science 226: 1342-1344.

Owens MJ, Nemeroff CB (1991). Physiology and pharmacology of corticotropin-releasing factor. Pharmacol Rev 43: 425-473.

Peñalva RG, Flachskamm C, Zimmermann S, Wurst W, Holsboer F, Reul JMHM et al (2002). Corticotropin-releasing hormone receptor type 1-deficiency enhances hippocampal serotonergic neurotransmission: an in vivo microdialysis study in mutant mice. Neuroscience 109: 253-266.

Porsolt RD, Bertin A, Jalfre M (1977a). Behavioral despair in mice: a primary screening test for antidepressants. Arch Int Pharmacodyn Ther 229: 327-336.

Porsolt RD, Le Pichon M, Jalfre M (1977b). Depression: a new animal model sensitive to antidepressant treatments. Nature 266: 730-732.

Price ML, Curtis AL, Kirby LG, Valentino RJ, Lucki I (1998). Effects of corticotropin-releasing factor on brain serotonergic activity. Neuropsychopharmacology 18: 492-502.

Price ML, Kirby LG, Valentino RJ, Lucki I (2002). Evidence for corticotropin-releasing factor regulation of serotonin in the lateral septum during acute swim stress: adaptation produced by repeated swimming. Psychopharmacology 162: 406-414.

Price ML, Lucki I (2001). Regulation of serotonin release in the lateral septum and striatum by corticotropin-releasing factor. J Neurosci 21: 2833-2841.

Raadsheer FC, Hoogendijk WJG, Stam FC, Tilders FJH, Swaab DF (1994). Increased numbers of corticotropin-releasing hormone expressing neurons in the hypothalamic paraventricular nucleus of depressed patients. Neuroendocrinology 60: 436-444.
Raadsheer FC, Van Heerikhuize JJ, Lucassen PJ, Hoogendijk WJG, Tilders FJH, Swaab DF (1995). Corticotropin-releasing hormone mRNA levels in the paraventricular nucleus of patients with Alzheimer's disease and depression. Am J Psychiatry 152: 1372-1376.

Ressler KJ, Nemeroff CB (2000). Role of serotonergic and noradrenergic systems in the pathophysiology of depression and anxiety disorders. Depression Anxiety 12: 2-19.

Reul JMHM, Holsboer F (2002). Corticotropin-releasing hormone receptors 1 and 2 in anxiety and depression. Curr Opin Pharmacol 2: 23-33.

Reul JMHM, Labeur MS, Grigoriadis DE, De Souza EB, Holsboer F (1994). Hypothalamic-pituitary-adrenocortical axis changes in the rat after long-term treatment with the reversible monoamine oxidase-A inhibitor moclobemide. Neuroendocrinology 60: 509-519.

Reul JMHM, Stec I, Söder M, Holsboer F (1993). Chronic treatment of rats with the antidepressant amitriptyline attenuates the activity of the hypothalamic-pituitary-adrenocortical system. Endocrinology 133: 312-320.

Roche M, Commons KG, Peoples A, Valentino RJ (2003). Circuitry underlying regulation of the serotonergic system by swim stress. J Neurosci 23: 970-977.

Rueter LE, Fornal CA, Jacobs BL (1997). A critical review of 5-HT brain microdialysis and behavior. Rev Neurosci 8: 117-137.

Rueter LE, Jacobs BL (1996). Changes in forebrain serotonin at the light-dark transition: correlation with behaviour. Neuroreport 7 : 1107-1111.

Ruggiero DA, Underwood MD, Rice PM, Mann JJ, Arango V (1999). Corticotropic-releasing hormone and serotonin interact in the human brainstem: behavioral implications. Neuroscience 91: 1343-1354.

Sakanaka M, Shibasaki T, Lederis K (1987). Corticotropin releasing factor-like immunoreactivity in the rat brain as revealed by a modified cobalt-glucose oxidase-diaminobenzidine method. J Comp Neurol 260: 256-298.

Schulz DW, Mansbach RS, Sprouse J, Braselton JP, Collins J, Corman $M$ et al (1996). CP-154,526: a potent and selective nonpeptide antagonist of corticotropin releasing factor receptors. Proc Natl Acad Sci USA 93: 10477-10482.

Singh VB, Corley KC, Phan TH, Boadle-Biber MC (1990). Increases in the activity of tryptophan hydroxylase from rat cortex and midbrain in response to acute or repeated sound stress are blocked by adrenalectomy and restored by dexamethasone treatment. Brain Res 516: 66-76.

Smith GW, Aubry JM, Dellu F, Contarino A, Bilezikjian LM, Gold LH et al (1998). Corticotropin releasing factor receptor 1deficient mice display decreased anxiety, impaired stress response, and aberrant neuroendocrine development. Neuron 20: 1093-1102.

Swanson LW, Sawchenko PE, Rivier J, Vale WW (1983). Organization of ovine corticotropin-releasing factor immunoreactive cells and fibers in the rat brain: an immunohistochemical study. Neuroendocrinology 36: 165-186.

Sze PY, Neckers L, Towle AC (1976). Glucocorticoids as a regulatory factor for brain tryptophan hydroxylase. J Neurochem 26: $169-173$.

Timpl P, Spanagel R, Sillaber I, Kresse A, Reul JMHM, Stalla GK et al (1998). Impaired stress response and reduced anxiety in mice lacking a functional corticotropin-releasing hormone receptor 1. Nat Genet 19: 162-166.

Valentino RJ, Liouterman L, Van Bockstaele EJ (2001). Evidence for regional heterogeneity in corticotropin-releasing factor interactions in the dorsal raphe nucleus. J Comp Neurol 435: 450-463.

Van Pett K, Viau V, Bittencourt JC, Chan RKW, Li HY, Arias C et al (2000). Distribution of mRNAs encoding CRF receptors in brain and pituitary of bat and mouse. J Comp Neurol 428: 191-212. 
Von Bardeleben U, Holsboer F (1989). Cortisol response to a combined dexamethasone-hCRH challenge in patients with depression. J Neuroendocrinol 1: 485-488.

Wong ML, Webster EL, Spokes H, Phu P, Ehrhart-Bornstein M, Bornstein S et al (1999). Chronic administration of the nonpeptide CRH type 1 receptor antagonist antalarmin does not blunt hypothalamic-pituitary-adrenal axis responses to acute immobilization stress. Life Sci 65: L53-L58.
Wright IK, Upton N, Marsden CA (1992). Effect of established and putative anxiolytics on extracellular 5-HT and 5-HIAA in the ventral hippocampus of rats during behaviour on the elevated X-maze. Psychopharmacology 109: 338-346.

Zobel AW, Nickel T, Künzel HE, Ackl N, Sonntag A, Ising M et al (2000). Effects of the high-affinity corticotropin-releasing hormone receptor 1 antagonist R121919 in major depression: the first 20 patients treated. J Psychiatr Res 34: 171-181. 